\title{
Neurovirulent Simian \\ Immunodeficiency Virus Infection \\ Induces Neuronal, Endothelial, and \\ Glial Apoptosis
}

\author{
D. Cory Adamson, ${ }^{{ }^{\dagger}}{ }^{\dagger}$ Ted M. Dawson, ${ }^{{ }^{\dagger}}$ M. Christine Zink, ${ }^{\neq}$ \\ Janice E. Clements, ${ }^{\ddagger}$ and Valina L. Dawson*\$\$ \\ Departments of ${ }^{*}$ Neuroscience, ${ }^{\dagger}$ Neurology, ${ }^{\ddagger}$ Comparative Medicine, \\ and ${ }^{\$}$ Physiology, Johns Hopkins University School of Medicine, \\ Baltimore, Maryland, U.S.A.
}

\begin{abstract}
Background: Studies of human immunodeficiency virus type 1 (HIV-1) associated dementia have shown neuronal loss in discrete areas. The presence and mechanism of neuronal death, however, has remained quite elusive. One mechanism of cell death, apoptosis, has been clearly demonstrated outside the central nervous system (CNS) in HIV-1 infection but has not been firmly established within the CNS. Therefore, we set out to ascertain whether neuronal cell loss in simian immunodeficiency virus (SIV) encephalitis, an animal model of HIV-I-associated dementia, is a result of apoptosis.

Materials and Methods: With the aid of an in situ technique for identifying the 3 '-OH ends of newly fragmented DNA characteristic of apoptosis, in conjunction with specific detected morphological criteria via light microscopy, we have examined encephalitic and nonencephalitic brains of macaques infected with a neurovirulent, neuroendotheliotropic strain of SIV to see if virus is
\end{abstract}

spatially associated with apoptosis of neurons and nonneuronal cell types.

Results: We demonstrate the presence of DNA damage, indicative of apoptosis, in neurons, endothelial cells, and glial cells of the CNS of SIV-infected macaques. Furthermore, we observe an association between the localization of cells with significant DNA fragmentation and perivascular inflammatory cell infiltrates containing SIVinfected macrophages and multinucleated giant cells. Quantitative analysis reveals significantly more cells with DNA fragmentation in the CNS of macaques infected with neurovirulent, neuroendotheliotropic SIV strains as compared with strictly lymphocyte-tropic SIV strains and SIV negative controls.

Conclusions: Our findings of apoptosis in SIV-infected CNS may potentially lead to a better understanding of the AIDS dementia complex, ultimately providing a basis for better treatments.

\section{INTRODUCTION}

Fifteen to twenty percent of adults with acquired immunodeficiency syndrome (AIDS) disease due to human immunodeficiency virus type 1 (HIV-1) infection develop progressive dementia

Address correspondence and reprint requests to: Valina Dawson, Department of Neurology, Johns Hopkins University School of Medicine, 600 North Wolfe Street/Pathology 2-210, Baltimore, MD 21287, U.S.A.
$(1,2)$. AIDS dementia occurs without the direct infection of neurons or astrocytes by HIV-l. Attempts have been made to correlate structural changes seen by routine neuropathology, such as white matter pallor, breakdown of the bloodbrain barrier (BBB), microglial nodules, and multinucleated giant cells, with AIDS dementia. However, these pathologic studies do not provide a satisfying explanation for the clinical observations $(2-6)$. 
TABLE 1. Mean age, postmortem delay, and clinical outcome of $S_{\text {IV }} 239$ infection

\begin{tabular}{lccccc}
\hline Macaques & $\boldsymbol{n}$ & $\begin{array}{c}\text { Age } \\
\text { (years) }\end{array}$ & $\begin{array}{c}\text { Postmortem } \\
\text { Delay (hr) }\end{array}$ & $\begin{array}{c}\text { CNS Virus } \\
\text { Isolation }\end{array}$ & $\begin{array}{c}\text { Health } \\
\text { Status }\end{array}$ \\
\hline SIV-positive, neurovirulent & 3 & 4 & 1.5 & Yes & $\begin{array}{c}\text { Low CD4 cts, pneumonia, } \\
\text { encephalitis } \\
\text { Low CD4 cts, pneumonia, } \\
\text { no encephalitis } \\
\begin{array}{c}\text { SIV-positive, non- } \\
\text { neurovirulent }\end{array}\end{array}$ \\
$\begin{array}{l}\text { SIV-negative control } \\
\text { Healthy }\end{array}$
\end{tabular}

The HIV-1 virus frequently enters the central nervous system (CNS) and primarily infects and undergoes active replication in mononuclear phagocytes, microglia, and multinucleated giant cells $(7,8)$. Even though HIV-1 does not directly infect neurons, there is neuronal loss in the cortex and retina in AIDS dementia. Thus, neuronal cell injury and death probably occurs through indirect mechanisms from the release of toxic substances from adjacent HIV-infected cells (9). The HIV-1 coat protein gp 120, which is shed by the virus, could contribute to cell death through indirect activation of the $\mathrm{N}$-methyl-D-aspartate (NMDA) glutamate receptor or voltage-dependent calcium channels (10). Previous in vitro studies have suggested that prolonged NMDA receptor activation may lead to neuronal apoptotic cell death (11). Neuronally derived nitric oxide (NO) may contribute to gpl20-induced cell death, since inhibitors of NO synthase (NOS) prevent neurotoxicity (12). The HIV-1 coat proteins gp 160, gp120, and gp4l stimulate cultures of astrocytes and microglia to produce tumor necrosis factor $\alpha(\mathrm{TNF} \alpha)$, interleukin $1 \beta$ (IL-1 $\beta$ ), and immunologic NOS (iNOS) (12-15). Activated macrophages and microglia also secrete eicosanoids, oxygen free radicals, and platelet activating factor (PAF), which may further contribute to neuronal and astrocytic injury. Interestingly, TNF $\alpha$, PAF, and iNOS are uniquely elevated in the brain or cerebral spinal fluid of patients with AIDS who have neurologic deficits including dementia (Refs. 16 and 17, and B. Wildemann, submitted). Thus, these pro-inflammatory cytokines probably initiate processes that ultimately lead to the clinical manifestations of AIDS dementia.

Despite the likelihood that pro-inflammatory cytokines initiate neuronal and astrocytic injury in AIDS dementia, the underlying molecular mechanisms of cell death have yet to be clarified.
Using postmortem CNS tissue, recent studies have provided evidence to suggest the existence of DNA fragmentation in adult $(18,19)$ and pediatric (20) cases with HIV-l encephalitis. These studies may be confounded by significantly prolonged postmortem intervals (PMI) with artifactual DNA fragmentation (D. C. Adamson, T. M. Dawson, V. L. Dawson, unpublished observations). We utilize an AIDS dementia complex (ADC) animal model in which we maintained PMI below the critical threshold for artifactual DNA fragmentation. We show striking amounts of apoptosis, as indicated by terminal transferase dUTP nicked end labeling (TUNEL) of DNA fragments in neurons, astrocytes, microglia, oligodendrocytes, and endothelial cells in an animal model of ADC, the neurovirulent, neuroendotheliotropic simian immunodeficiency virus (SIV)-infected rhesus macaques, and we suggest that similar processes may occur in AIDS dementia. Moreover, TUNEL-positive cells appear to be a reliable marker for assessment of neuropathologic changes that accompany SIV and perhaps HIV-1 infection.

\section{MATERIALS AND METHODS}

\section{SIV Strains, Macaques, and Tissue Procurement}

Nine SIV-seronegative juvenile rhesus macaques obtained from the Johns Hopkins University breeding colony were used for these studies. The monkeys were sedated with ketamine followed by halothane anesthesia. Six monkeys received an intracerebral inoculation (100 $\mu$ l into each cerebral hemisphere) of a macrophage-tropic strain of SIV, SIV/17E-Br, which had been isolated from the brain of a macaque with severe encephalitis $(21,22)$ (see Table 1 for description 
of macaques). The animals were euthanized by exsanguination after the development of clinical signs of immunosuppression and/or neurological disease (4-12 months after inoculation). CNS tissue was harvested using sterile technique and biohazard precautions, fixed in $10 \%$ formalin, and processed for histology. CNS tissue was harvested from three uninfected juvenile macaques and used as virus-negative controls.

\section{In Situ Terminal Transferase dUTP Nicked End Labeling Analysis}

Whole brains from SIV-infected and uninfected control macaques were embedded in agarose and then cut into $0.5-\mathrm{cm}$ transverse sections with a deli-slicer and fixed in $10 \%$ buffered formaldehyde for $48 \mathrm{hr}$. After removing agarose, the tissue was dehydrated through a graded series of alcohols and embedded in paraffin. Four- to tenmicron-thick microtome sections were cut and mounted on alum- and gelatin-coated slides. After having been deparaffinized by heating at $60^{\circ} \mathrm{C}$ for $30 \mathrm{~min}$ and washing twice in xylene for a total of $10 \mathrm{~min}$, sections were rehydrated through a graded series of ethanol and double distilled water $\left(\mathrm{ddH}_{2} \mathrm{O}\right)$.

The TUNEL technique was carried out as previously described by Gavrieli et al. (23) with some modifications. After a 5-min wash with 10 $\mathrm{mM}$ Tris- $\mathrm{HCl}(\mathrm{pH} \mathrm{8})$, sections were digested with proteinase $\mathrm{K}(40 \mu \mathrm{g} / \mathrm{ml})$ in $10 \mathrm{mM}$ Tris- $\mathrm{HCl}(\mathrm{pH}$ 8) for $15 \mathrm{~min}$ at room temperature (RT) and washed $(4 \times 2 \mathrm{~min})$ in $\mathrm{ddH}_{2} \mathrm{O}$. Sections were then preincubated for $15 \mathrm{~min}$ at RT in terminal deoxynucleotidylexotransferase (TdT) buffer (30 $\mathrm{mM}$ Tris- $\mathrm{HCl}, \mathrm{pH} 7.2 / 140 \mathrm{mM}$ sodium cacodylate $/ 1 \mathrm{mM}$ cobalt chloride), and incubated for 90 min at $37^{\circ} \mathrm{C}$ with $100 \mu \mathrm{l}$ of TdT buffer with $0.5 \mu \mathrm{l}$ $\mathrm{TdT} / \mu \mathrm{l}$ and $40 \mu \mathrm{l}$ digoxigenin $1 \mathrm{l}-\mathrm{dUTP}$ in a moist chamber. Preliminary experiments comparing the use of biotin-conjugated dUTP to digoxigenin-conjugated dUTP in the TUNEL method showed the later to be the superior reagent (data not shown). After a 10 -min $\mathrm{ddH}_{2} \mathrm{O}$ wash, the reaction was stopped by transferring the sections to $2 \times \mathrm{SSC}$ buffer $(300 \mathrm{mM} \mathrm{NaCl} / 30 \mathrm{mM}$ sodium citrate) for $15 \mathrm{~min}$ at RT. The sections were then washed in phosphate-buffered saline (PBS) for 5 min, blocked with $2 \%$ bovine serum albumin (BSA) in PBS for 20 min at RT, and washed again for $2 \mathrm{~min}$ in $\mathrm{ddH}_{2} \mathrm{O}$. Endogenous peroxidases were inactivated by incubating the sections for 5 min in $3 \% \mathrm{H}_{2} \mathrm{O}_{2}$ at RT and then washed in PBS
$(2 \times 10 \mathrm{~min})$. The sections were screened with biotin conjugated anti-digoxin antibody (1:10000 in PBS supplemented with $0.1 \%$ bovine serum albumin (BSA) and $0.1 \%$ Triton X-100 [Sigma Immuno Chemicals, St. Louis, MO, U.S.A.]) $12-16 \mathrm{hr}$ at $4^{\circ} \mathrm{C}$. After being washed twice with PBS for a total of $10 \mathrm{~min}$, the sections were incubated for $30 \mathrm{~min}$ at $37^{\circ} \mathrm{C}$ in Vectastain extraavidin peroxidase standard solution (Vector Laboratories, Burlingame, CA, U.S.A.). Following three 5-min washes with PBS, the sections were incubated in $0.1 \%$ biotinyl tyramide (NEN Research Products, Boston, MA, U.S.A.) in PBS for $20 \mathrm{~min}$ at RT. Biotinyl tyramide precipitates additional biotin-conjugated molecules onto the original biotinylated antibody. The sections were rinsed in PBS $(3 \times 10 \mathrm{~min})$ and this was followed by incubating in the extra-avidin peroxidase standard solution for $30 \mathrm{~min}$ at $37^{\circ} \mathrm{C}$. The sections were then washed in PBS $(3 \times 10 \mathrm{~min})$, stained 10-15 min at RT with Vector Laboratories VIP as a substrate. After the developing reaction was stopped with water, the sections were counterstained with nuclear fast red (NFR) for 2 min, dehydrated through a series of graded ethanol, washed in xylene for $10 \mathrm{~min}$, and finally coverslipped in DPX Mountant (Fluka, Buchs, Switzerland). Positive controls were incubated with DNase I $(1 \mu \mathrm{g} / \mathrm{ml})$ in TdT buffer for $10 \mathrm{~min}$ at RT before the incubation in biotinylated nucleotides. Negative controls were performed by omitting the TdT. DNase, TdT, and digoxigenin 11-dUTP were purchased from Boehringer Mannheim (Indianapolis, IN, U.S.A.).

\section{Immunohistochemistry}

Differential immunohistochemistry was used to identify specific cell types. Briefly, sections (7- to $10-\mu \mathrm{m}$ thick) from infected and uninfected macaques were labeled with the TUNEL method. To rid the TUNEL-labeled sections of remaining peroxidases, sections were thoroughly washed with PBS and treated with $3 \% \mathrm{H}_{2} \mathrm{O}_{2}$ before immunolabeling. The sections were then washed in $\mathrm{ddH}_{2} \mathrm{O}$ and PBS (pH 7.4) for 5 min each. Sections were blocked with $2 \%$ normal goat serum in PBS for $\mathbf{2 0}$ min at RT in a humidity chamber. Various primary antibodies were applied for $12-16 \mathrm{hr}$ at $4^{\circ} \mathrm{C}$. One set of experiments used monoclonal antibody KK4l (a gift from Dr. Karen Kent) as the primary antibody (1:10 diluted in PBS) to identify SIV transmembrane glycoprotein. Another series of experiments used lectin histo- 
chemistry with RCA- 1 antibody (1:200 diluted in PBS) to identify macrophages, microglia, and endothelial cells. Glial fibrillary acidic protein and factor VIII antibodies (1:200 diluted in PBS) were used to label astrocytes and endothelial cells, respectively. After two 10-min washes with PBS, sections were incubated in biotinylated goat antibody (1:200 diluted in PBS) for $30 \mathrm{~min}$ at RT in humidity chambers, and then washed again with PBS $(2 \times 10 \mathrm{~min})$. The sections were then incubated with $2 \% \mathrm{H}_{2} \mathrm{O}_{2}$ in absolute methanol for 30 min at RT to inactivate endogenous peroxidases. The sections were then dipped in PBS followed by PBS $\times 20 \mathrm{~min}$. The sections were subsequently incubated in extra-avidin peroxidase standard solution for $30 \mathrm{~min}$ at $37^{\circ} \mathrm{C}$, rinsed with PBS $(2 \times 5 \mathrm{~min})$ and stained 5-10 min with DAB as a substrate. Sections were counterstained with NFR, dehydrated, and mounted. Staining repeated without the primary antibodies revealed no background nonspecific staining (data not shown). Immunolabeling before TUNEL analysis gave similar results (data not shown), further supporting the specificity of the procedures.

\section{Quantitation of Cell Numbers}

TUNEL-positive cells were quantified using the IPLab Spectrum analysis software by Signal Analytics Corporation. Three representative lowpower fields encompassing approximately $80 \%$ of the entire section from three stained sections from each control and experimental animal were scanned with a Sony color video camera and subsequently analyzed on a Macintosh PowerPC $8100 / 80 \mathrm{AV}$ computer. Using a micron ${ }^{2} / \mathrm{pixel}^{2} \mathrm{ra}$ tio of 14.0625 for the IPLab software, data obtained in pixels was converted to $\mu \mathrm{m}^{2}$ of label per $\mathrm{cm}^{2}$ of tissue scanned, entered onto an Excel spreadsheet, and analyzed by the statistical packages StatView and SuperAnova. Only labeled objects with an area between 28.27 and 113.10 $\mu \mathrm{m}^{2}$ were considered, corresponding to cells with labeled nuclei of 6- to $12-\mu \mathrm{m}$ diameters. Rare objects were labeled outside of these dimensions. For all quantitative data, significant overall $F$ values were obtained by using a oneway, between-groups analysis of variance. Specific comparisons on all possible pairwise combinations were made with Student's $t$ test for independent means. Significance was determined at $p<0.05$.

\section{RESULTS}

\section{Pathologic Characteristics of SIV-Infected Rhesus Macaques}

Microscopic examination of tissues from the six inoculated macaques demonstrate that three animals have typical SIV encephalitis, with glial nodules, perivascular cuffing with macrophages and multinucleated giant cells, and diffuse hypercellularity of the parenchyma. Immunohistochemistry staining using antibody KK41, and in situ hybridization for viral RNA are highly positive, indicating an abundance of viral gene products in the CNS. Cocultivation of brain homogenates with susceptible CEMx174 cells results in the formation of syncytia, confirming the presence of virus in the CNS of these three animals.

The other three macaques do not have any lesions in the CNS. Immunohistochemistry staining and in situ hybridization on CNS tissues, and coculture of brain homogenates with CEMxl74 cells are all negative, indicating that neither virus nor virus gene products are present in the CNS of these animals (21).

\section{TUNEL in Neurovirulent, Neuroendotheliotropic SIV-Infected Monkeys}

In uninfected control monkeys TUNEL is rarely identified in neurons and in oligodendrocytes (Fig. 1A). The SIV-infected monkeys without CNS lesions exhibit occasional TUNEL positive neurons and astrocytes (Fig. 1B). In marked contrast, there is a striking number of TUNEL-positive cells in SIV-infected monkeys with SIV encephalitis in all areas of the brain including gray matter and white matter throughout the cortex and subcortical structures (Fig. 1C). To ensure the specificity of the labeling procedure, control experiments performed on adjacent sections demonstrate that TUNEL is always present following DNA fragmentation due to the exogenous application of DNAse-1 enzyme. In addition, the elimination of terminal transferase from the labeling procedures results in no TUNELpositive cells (data not shown).

\section{Quantitation of TUNEL in SIV-Infected Monkeys}

We quantitated the number of TUNEL-positive cells using a computer-assisted cell-counting device. There is a striking number of TUNELpositive cells in the SIV-infected monkeys with 

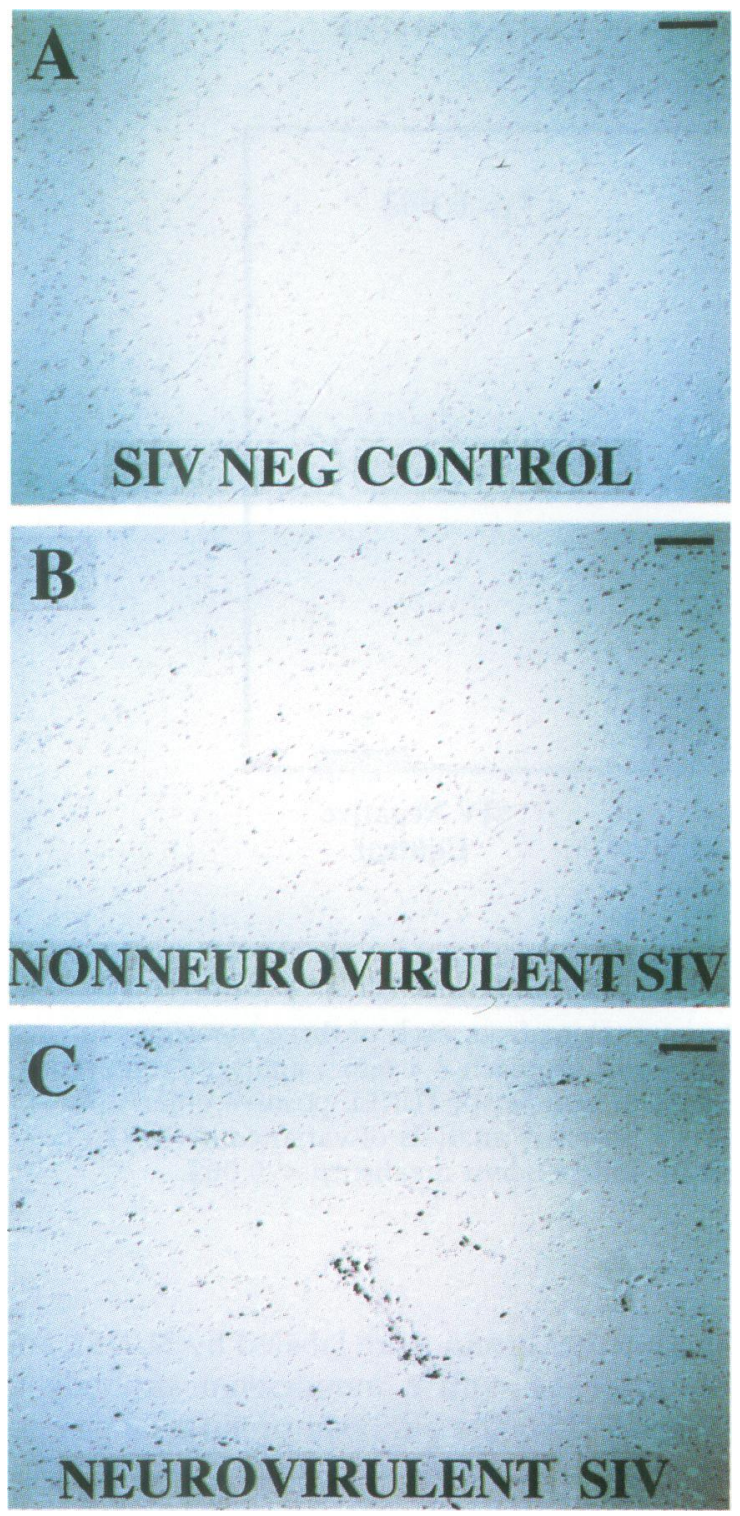

FIG. 1. Neurovirulent SIV produces a marked increase in the number of TUNEL positive cells in the macaque CNS

Low-power view of sagittal brain sections show rare TUNEL-positive cells in the healthy macaque CNS (A), a moderate increase in the number of TUNELpositive cells in the non-neurovirulent SIV-infected macaque CNS (B), and a marked increase in the number of TUNEL-positive cells in the neurovirulent SIV-infected macaque CNS (C). TUNEL label appears scattered throughout cortical and subcortical areas in a random fashion. Scale bars $=100 \mu \mathrm{m}$.

encephalitis compared with controls and SIVinfected monkeys without encephalitis (Fig. 2). Analysis of the individual $4.3-\mathrm{mm}^{2}$ images counted on each section reveal a preponderance of cells with nuclei approximately $6-9 \mu \mathrm{m}$ in diameter, occasional cells with 10- to $12-\mu \mathrm{m}$ nuclei diameters and rare cells with larger dimensions. These values show that in all three groups the vast majority of CNS cells identified by TUNEL are those with the smallest nuclear size, which probably represent oligodendrocytes and microglia (data not shown).

To determine whether we may have overestimated the number of apoptotic cells due to the postmortem interval, we performed TUNEL analysis on serial sagittal sections of normal male rat brains at postmortem intervals ranging from 0 to $24 \mathrm{hr}$. Our analysis indicates that TUNEL is present only after $12 \mathrm{hr}$ and, continues to increase up to $24 \mathrm{hr}$ postmortem interval (data not shown). All macaque CNS tissue is fixed within $1.5 \mathrm{hr}$; thus a very small number of apoptotic cells would be present strictly due to terminal events.

\section{Neurons, Glia, and Endothelial Cells Are TUNEL Positive}

The neurovirulent, neuroendotheliotropic SIVinfected monkeys show neuropathological changes that are similar to those observed in humans with HIV encephalitis, including multinucleated giant cells and microglial nodules. Microglial nodules consistently show extensive TUNEL throughout the nodule (Fig. 3A). In addition, there is associated TUNEL of neurons and glia around the periphery of most microglial nodules. We also observe an extensive amount of TUNEL around blood vessels of all sizes (Fig. 3B). TUNEL occurs in hypercellular areas of perivascular cuffing suggestive of dying resident perivascular macrophages or of blood-borne macrophages invading the brain parenchyma. Endothelial cells are frequently TUNEL positive, and this finding suggests that the blood-brain barrier may be compromised (24). Multinucleated giant cells are frequently TUNEL positive (Fig. $3 \mathrm{C}$ and D). We frequently observe TUNELpositive cells around the periphery of multinucleated giant cells (Fig. $3 \mathrm{C}$ and D).

Astrocytes labeled with glial fibrillary acidic protein (GFAP) antibody are frequently TUNEL positive in monkeys infected with the neurovirulent, neuroendotheliotropic SIV strain (Fig. 4A). Rare cells displaying apoptotic bodies are occasionally observed (Fig. 4B). Based on morphological criteria, the most abundant cell type exhibiting TUNEL appears to be oligodendrocytes (data not shown). Although an adequate bio- 


\section{Central Nervous System TUNEL after SIV Infection}

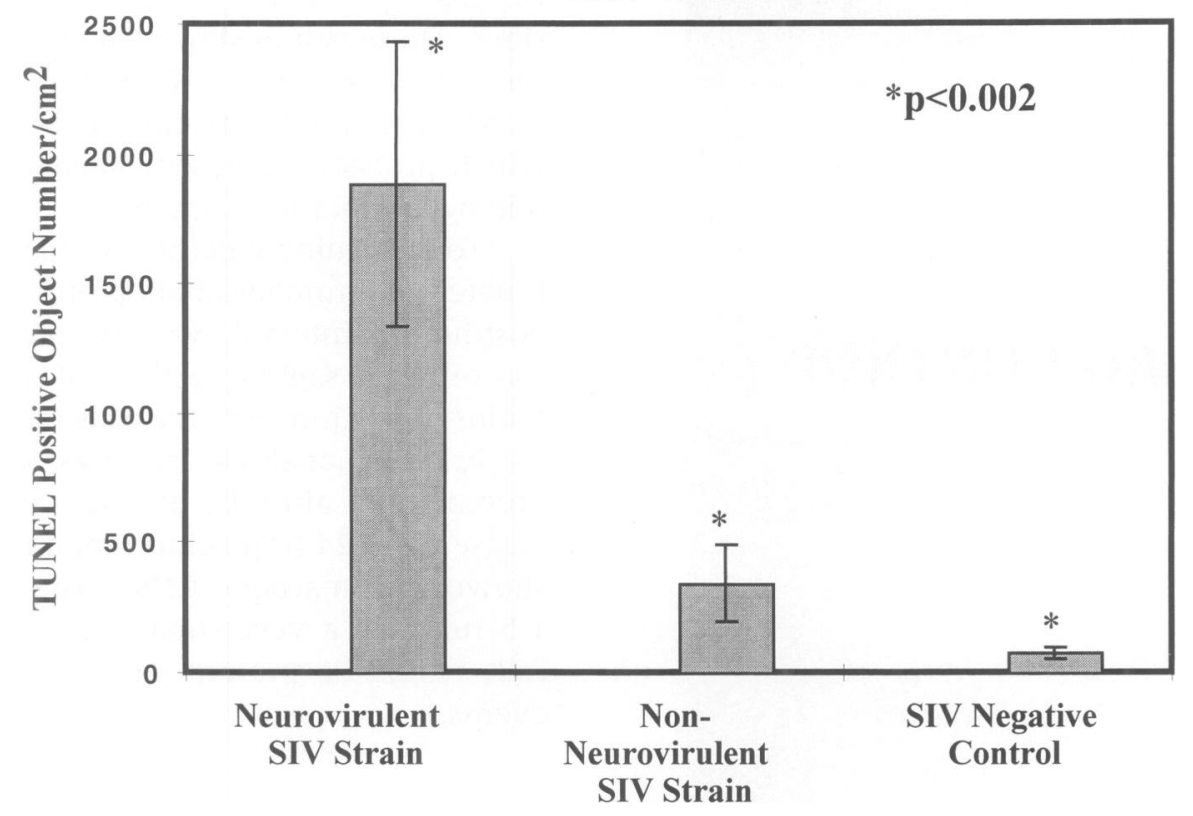

FIG. 2. Neurovirulent SIV infection results in a significant quantitative increase in TUNEL-positive cells in the macaque CNS

Data from three images per section were analyzed on three different sections from each of three macaques in each experimental group and averaged to yield the final results. The three images (each $4.3 \mathrm{~mm}^{2}$ ) analyzed represented more than $80 \%$ of the total area per section. Data are reported as mean number of TUNEL-positive objects per $\mathrm{cm}^{2} \pm \operatorname{SEM}(n=3)$. Significant overall values were obtained using a one-way analysis of variance (ANOVA) between groups. Significance was determined by the Student's $t$ test for independent means; ${ }^{*} p<0.002$.

chemical marker for oligodendrocytes in simian CNS is not available, their peri-neuronal location, abundance in white matter, and lack of staining with antibodies to astrocytic, neuronal, and microglial antigens make their identification possible. Endothelial cells are frequently TUNEL positive and were easily identified based on location and structure (Fig. 4C). These cells have flattened nuclei lining the lumen of both large vessels and capillaries. Double labeling with factor VIII-related antigen confirms this observation (Fig. 4D). Occasional microglia or macrophages are also TUNEL positive as indicated by colocalization of TUNEL with RCA-1 (Fig. 4E). Several neurons are TUNEL positive, and they tend to occur in isolation often adjacent to multinucleated giant cells and/or microglial nodules.

\section{SIV Antigen Colocalizes with TUNEL-Positive Cells in the CNS}

To ascertain the possible role of SIV infection in DNA fragmentation, several sections from each experimental group were labeled by TUNEL and then screened with a monoclonal antibody to SIV gp4l (25). The antibody produces a characteristic predominantly cytoplasmic staining pattern of SIV-infected cells. Double-labeled cells are invariably seen in clusters, particularly amid inflammatory foci, perivascular cuffing, and multinucleated giant cells (Fig. 5). In virtually all cases where TUNEL is observed, TUNEL-positive cells are also SIV positive or are located in extremely close proximity to SIV positive cells (Fig. 5).

\section{DISCUSSION}

In the present study, we demonstrate that TUNEL-positive cells are strikingly prevalent in the central nervous system of monkeys infected with a neurovirulent, neuroendotheliotropic strain of SIV. In contrast to previous reports, which did not attempt to correlate the presence of apoptotic CNS cells with dementia $(19,26)$, 

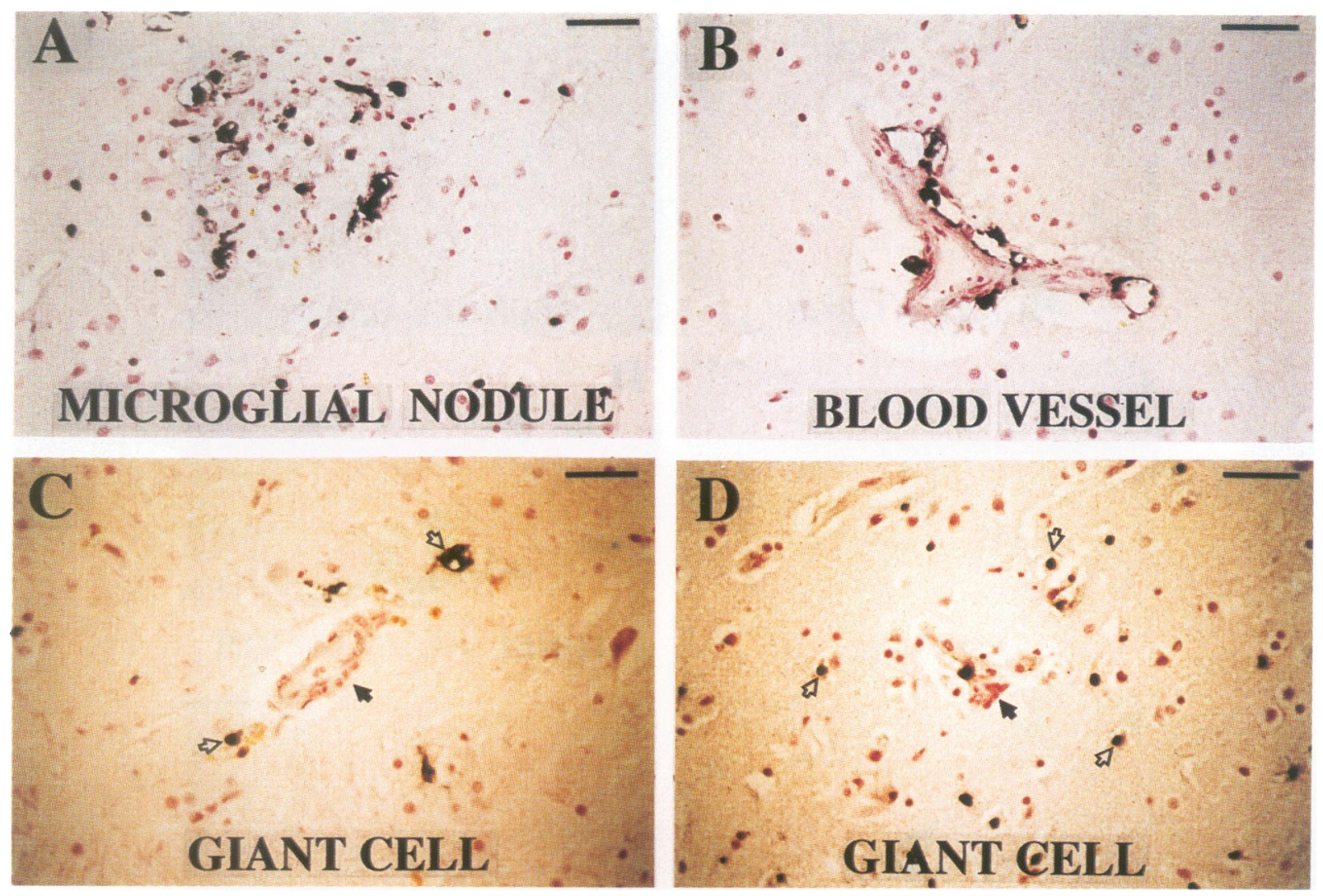

FIG. 3. TUNEL-positive cells are seen in pathological hallmarks of SIV infection of the CNS

High-power view of macaque CNS infected with neurovirulent SIV shows TUNEL-positive cells amidst microglial nodules (A). Note that occasional cells with morphological appearance of neurons are TUNEL positive (arrow). Blood vessels are frequently TUNEL positive, usually in association with perivascular cuffing (B). Multinucleated giant cells are usually TUNEL positive (D, closed arrow) or are found closely associated with other TUNEL-positive cells (C and D, open arrows). Scale bars $=100 \mu \mathrm{m}$.

our results demonstrate a strong correlation between neuronal loss due to apoptosis and dementia. TUNEL is present in a variety of cells, including neurons, oligodendrocytes, microglia, astrocytes, and endothelial cells. When SIV antigen is present, we always observe TUNEL colocalized or in close proximity. The presence of SIV antigen with TUNEL suggests a role for SIV in initiating or mediating DNA fragmentation. TUNEL is also frequently observed in or around inflammatory foci, perivascular cuffing, multinucleated giant cells, and microglial nodules.

The SIV infection in rhesus macaques is probably the most valuable animal model to study AIDS $(27,28)$. SIV infection produces similar pathologic and clinical changes as seen in HIV-1 encephalitis (27). Like HIV, SIV is a member of the lentivirus subfamily of retroviruses and causes persistent infection after infecting $\mathrm{CD}^{+}$lymphocytes and cells of the macrophage lineage. As in HIV-1 infection, there is a depletion of this subset of $\mathrm{T}$ cells and marked immunosuppression occurs, leading to opportunistic infections and oncogenic syndromes. AIDS-like disease in rhesus macaques can be induced with viruses that are strictly lymphocyte-trophic; however, observations in both HIV-1 and SIV infections indicate that viruses with a tropism for macrophages appear to cause CNS pathology $(27,29)$. HIV-1 and SIV have a similar overall genomic organization, with minor differences in the location of auxillary genes. Differences in epitopes of gp41 and gp120 of these viruses are thought to underlie the alterations in viral tropism and cytopathicity. Monkeys infected with the neurovirulent, neuroendotheliotropic SIV strain exhibit behavioral and motor disturbances reminiscent of patients with AIDS dementia (30), and thus have become a useful animal model for ADC. This SIV model of HIV dementia 


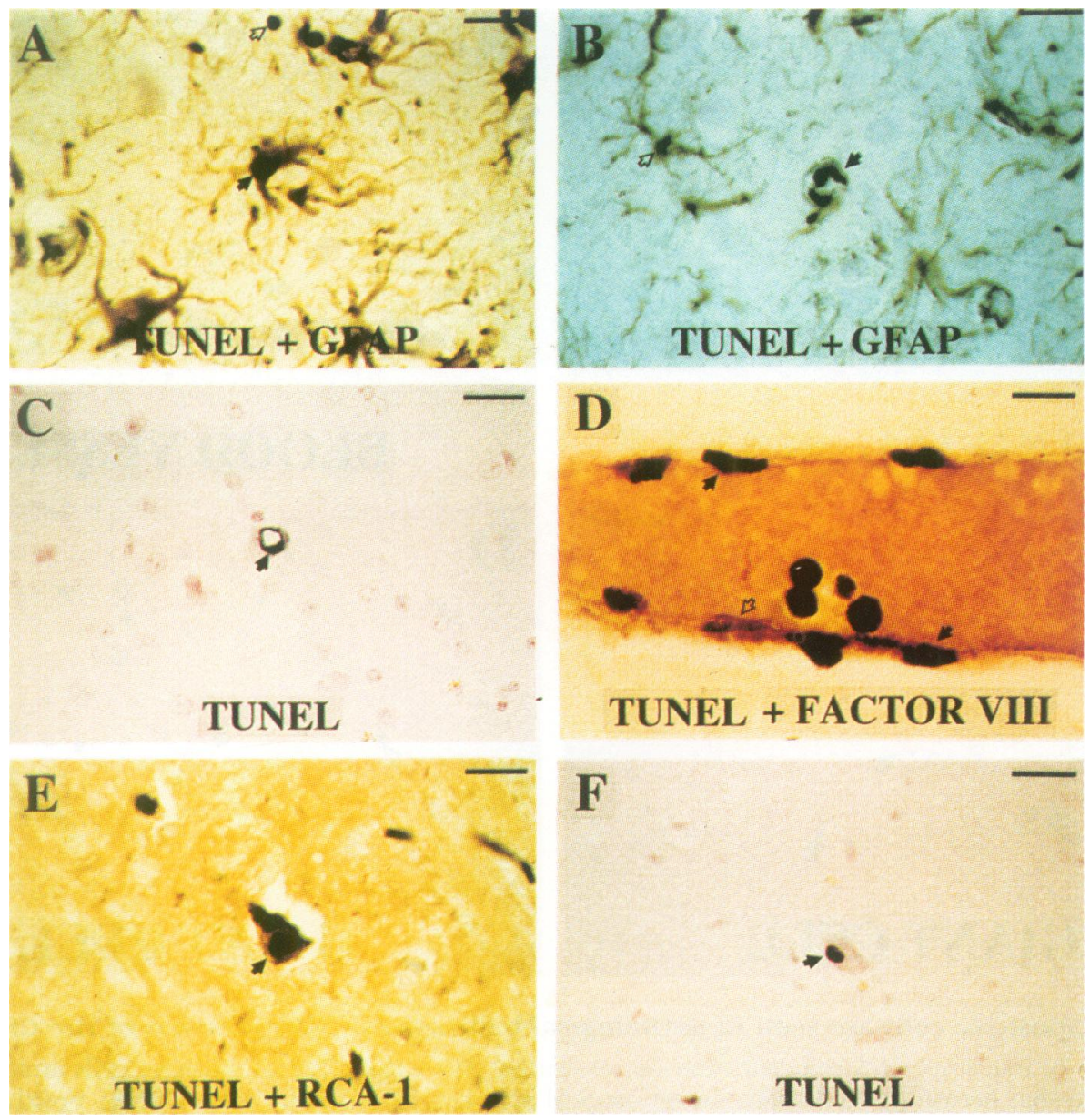

FIG. 4. Astrocytes, endothelial cells, microglia, and neurons are TUNEL positive in the SIV-infected macaque CNS

GFAP immunostaining demonstrates TUNEL-positive astrocytes (A, closed arrow). TUNEL-positive cells that are GFAP negative indicate the specificity of the double-labeling procedure (A and B, open arrows). Apoptotic bodies also appear TUNEL positive (B, closed arrow). Cells with distinct morphological characteristics of endothelial cells of the CNS vasculature $(\mathrm{C})$ and neurons $(\mathrm{F})$ demonstrate TUNEL reactivity. Factor VIII immunostaining demonstrates TUNEL-positive (D, closed arrow) and TUNEL-negative (D, open arrow) endothelial cells. RCA-1 immunostaining demonstrates TUNEL-positive cells of the microglia/macrophage lineage $(\mathrm{E})$. Scale bars $=40 \mu \mathrm{m}$.

has the inherent advantage of optimization of tissue procurement and preparation, variables which are inherently difficult to optimize in human postmortem studies. Indeed, our TUNEL analysis in human postmortem brain tissue from patients dying with AIDS dementia was complicated by false positive labeling due to postmortem intervals of greater than $12 \mathrm{hr}$ (data not shown).

The main finding of our study is that DNA fragmentation as indicated by TUNEL and morphometry occurs in the CNS of neurovirulent, neuroendotheliotropic SIV-infected monkeys. Thus, DNA fragmentation is a reliable marker of
CNS cellular injury in SIV infection and probably plays an important role in the clinical manifestations of SIV and HIV-1 infection. DNA fragmentation occurs in all forms of cell death and can be identified by TUNEL. However, the TUNEL we observe in cells with apoptotic bodies, condensed nuclei as well as the absence of inflammatory cells around a number of TUNELpositive cells and the frequent occurrence of TUNEL-positive cells in isolation suggests that we are observing apoptotic mechanisms. We cannot exclude the possibility that necrosis is accounting for some of the TUNEL we observe. The pathways to activation of apoptosis probably vary in 

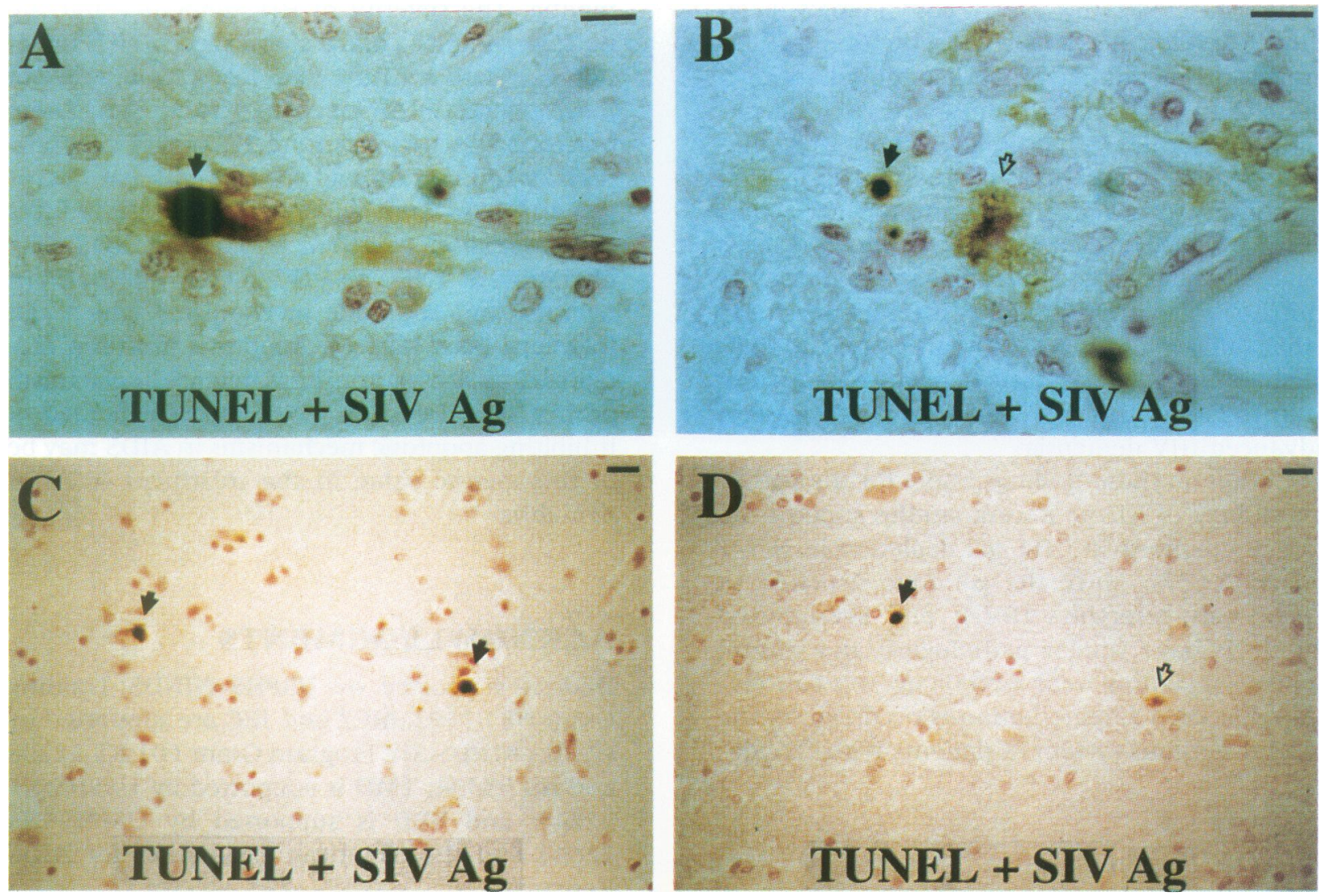

FIG. 5. TUNEL positive cells are usually SIV-infected or in close proximity to SIV-infected cells

High-power view of neurovirulent SIV-infected macaque CNS show colocalization of TUNEL label and SIV antigen (A-D, closed arrows) or close proximity of TUNEL labelled cells with SIV positive cells (B and D, open arrows). TUNEL-labeled nuclei appear black, and SIV immunostaining appears light brown. TUNEL- and SIV-positive cells are often seen in areas of hypercellularity (B). SIV antigen is occasionally detected in the absence of TUNEL indicating the specificity of the double-labeling method. Scale bars are $20 \mu \mathrm{m}$ (A and B) and $50 \mu \mathrm{m}$ (C and D).

different cell types, but the mechanism of death itself may occur via a final common pathway resulting in the morphological changes observed here. The signal for apoptosis may come from the environment or from within the cell itself. mRNA for TNF $\alpha$ and iNOS are markedly elevated in patients with HIV dementia. Both TNF $\alpha$ and NO can initiate apoptotic cell death in a variety of cell types (31-34). Thus, both TNF $\alpha$ and NO could serve as the initiators of the apoptosis. Simian homologs of these factors could have similar effects in SIV infection. Viral peptides, such as gp120, can initiate apoptotic cell death as seen by TUNEL in cortical cultures $(35,36)$.

The finding of numerous endothelial cells positive for TUNEL is of particular interest. Injury of these cells may have been induced by external factors such as cytokines, or may have been a direct result of virus infection since neuroviru- lent, neuroendotheliotropic strains of SIV replicate in CNS endothelial cells both in vivo and in vitro (24). The exact role of neuroendothelial cells in the neuropathogenesis of SIV-induced encephalitis or HIV-1 dementia is presently not known. Given the critical function of these cells in maintaining the BBB, in addition to permitting additional virus and/or virus-infected cells to enter the CNS, endothelial cell apoptosis would be expected to reduce the integrity of the BBB. Consistent with this notion is the compromise of BBB integrity in SIV encephalitis as indicated by loss of glucose transporter-1 staining (M. C. Zink and J. E. Clements, preliminary observations). Apoptotic endothelial cells have also been observed in the CNS of patients with HIV-1 encephalitis (D. Gabuzda, personal communication), and thus apoptotic endothelial cells may contribute to the clinical signs of AIDS dementia. 
Because SIV has never convincingly been shown to infect neurons, astrocytes, or oligodendrocytes, the finding of DNA fragmentation in these cells in SIV-infected animals with encephalitis but not infected animals without encephalitis suggests that soluble factors that induce or contribute to cell death are produced by cells during the inflammatory process. Apoptotic cells tended to be seen near glial foci and perivascular cuffs, sites with abundant macrophages and other inflammatory cells. In particular, the finding of potentially apoptotic neurons is consistent with the neuronal loss which is a key feature of advanced HIV dementia.

What do these findings imply for the pathophysiology of AIDS? Recent studies support the role of apoptosis in CD4 cell depletion in HIV-1 infection (37). Since the genomic structure of SIV closely resembles HIV-1, and SIV-infected monkeys have similar pathological and clinical changes including neuropathology, it is conceivable that DNA fragmentation is occurring in the central nervous system of patients with HIV de-

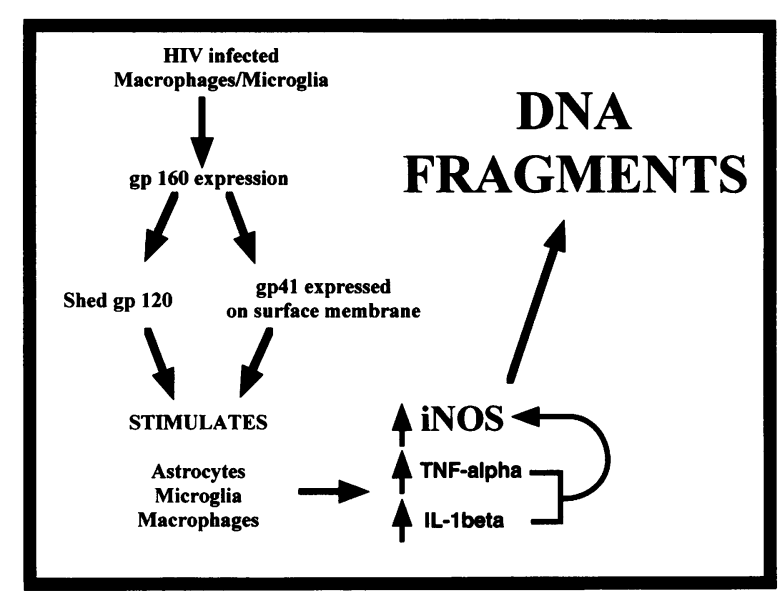

FIG. 6. Role of immunologic NOS (iNOS) in CNS apoptosis of AIDS dementia

The principal cells of the CNS infected by HIV-1 are those of the macrophage/microglia lineage. Infected cells produce viral proteins including gpl60 which eventually get cleaved into gp120 and gp41 fragments. gp4l remains membrane bound, whereas gpl 20 is presumably released into the extracellular milieu. These viral proteins stimulate astrocytes, microglia, and macrophages to secrete cytokines including TNF $\alpha$ and IL- $1 \beta$. In addition to viral proteins, these cytokines induce the expression of iNOS in these cells, which results in the liberation of nitric oxide (NO). In excessive amounts, NO becomes neurotoxic, inducing cell death pathways including apoptosis. mentia. The severity of HIV dementia and the neuropathologic changes observed in SIV infection correlate with the viral load and number of macrophages in the nervous system (38). These macrophages are presenting SIV or HIV coat proteins gpl60, gpl20, and gp4l to adjacent microglia and astrocytes, which subsequently induces the expression of TNF $\alpha$, IL- $1 \beta$ and iNOS. The liberation of TNF $\alpha$ and NO sets in motion both necrotic and apoptotic mechanisms which can fragment DNA (Fig. 6). Apoptosis has been recognized as a common host defense mechanism against viral infection (39). Strategies aimed at inhibiting apoptotic mechanisms in AIDS may be of therapeutic value in the treatment of AIDS dementia.

\section{ACKNOWLEDGMENTS}

DCA is supported by USPHS NINDS Training Grant NS 07392; MCZ and JEC are supported by USPHS NINDS SIV Program Grant P01 NS 32208 and NS 35334; TMD is supported by USPHS NS 22643; and VLD is supported by USPHS NS 22643 and the American Federation for AIDS Research.

\section{REFERENCES}

1. Navia BA, Jordan BD, Price RW. (1986) The AIDS dementia complex: I. Clinical features. Ann. Neurol. 19: 517-524.

2. Price RW, Brew B, Sidtis J, Rosenblum M, Scheck AC, Cleary P. (1988) The brain in AIDS: Central nervous system HIV-1 infection and AIDS dementia complex. Science 239: $586-592$.

3. Vazeux R, Lacroix-Ciaudo C, Blanche $S$, et al. (1992) Low levels of human immunodeficiency virus replication in the brain tissue of children with severe acquired immunodeficiency syndrome encephalopathy. Am. J. Pathol. 140: 137-144.

4. Falangola MF, Hanly A, Galvaocastro B, Petito CK. (1995) HIV infection of human choroid plexus-A possible mechanism of viral entry into the CNS. J. Neuropath. Exp. Neurol. 54: 497-503.

5. Falangola MF, Castro-Filho BG, Petito CK. (1994) Immune complex deposition in the choroid plexus of patients with acquired immunodeficiency syndrome. Ann. Neurol. 36: 437-440. 
6. Petito CK, Cash KS. (1992) Blood-brain barrier abnormalities in the acquired immunodeficiency syndrome: Immunohistochemical localization of serum proteins in postmortem brain. Ann. Neurol. 32: 658-666.

7. Koenig S, Gendelman HE, Orenstein JM, et al. (1986) Detection of AIDS virus in macrophages in brain tissue from AIDS patients with encephalopathy. Science 233: 10891093.

8. Wiley CA, Schrier RD, Nelson JA, Lampert PW, Oldstone MB. (1986) Cellular localization of human immunodeficiency virus infection within the brains of acquired immune deficiency syndrome patients. Proc. Natl. Acad. Sci. U.S.A. 83: 7089-7093.

9. Giulian D, Vaca K, Noonan CA. (1990) Secretion of neurotoxins by mononuclear phagocytes infected with HIV-1. Science 250: 1593-1596.

10. Lipton SA. (1992) Models of neuronal injury in AIDS: Another role for the NMDA receptor? Trends Neurosci. 15: 75-79.

11. Bonfoco E, Krainc D, Ankarcrona M, Nicotera P, Lipton SA. (1995) Apoptosis and necrosis: Two distinct events induced, respectively by mild and intense insults with $\mathrm{N}$-methyl-D-aspartate or nitric oxide/superoxide in cortical cell cultures. Proc. Natl. Acad. Sci. U.S.A. 92: 7162-7166.

12. Dawson VL, Dawson TM, Uhl GR, Snyder SH. (1993) Human immunodeficiency virus type 1 coat protein neurotoxicity mediated by nitric oxide in primary cortical cultures. Proc. Natl. Acad. Sci. U.S.A. 90: 3256-3259.

13. Koka P, He K, Camerini D, Tran T, Yashar SS, Merrill JE. (1995) The mapping of HIV-1 gp160 epitopes required for interleukin-1 and tumor necrosis factor alpha production in glial cells. J. Neuroimmunol. 57: 179-191.

14. Merrill JE, Koyanagi Y, Zack J, Thomas L, Martin F, Chen IS. (1992) Induction of interleukin- 1 and tumor necrosis factor alpha in brain cultures by human immunodeficiency virus type 1. J. Virol. 66: 2217-2225.

15. Yeung MC, Pulliam L, Lau AS. (1995) The HIV envelope protein gpl20 is toxic to human brain-cell cultures through the induction of interleukin- 6 and tumor necrosis factor-alpha. AIDS 9: 137-143.

16. Griffin DE, Wesselingh SL, McArthur JC. (1994) Elevated central nervous system prostaglandins in human immunodeficiency virus-associated dementia. Ann. Neurol. 35: 592-597.
17. Wesselingh SL, Power C, Glass JD, et al. (1993) Intracerebral cytokine messenger RNA expression in acquired immunodeficiency syndrome dementia. Ann. Neurol. 33: 576-582.

18. Petito CK, Roberts B. (1995) Evidence of apoptotic cell death in HIV encephalitis. Am. J. Pathol. 146: 1121-1130.

19. Adlebiassette $H$, Levy $Y$, Colombel $M$, et al. (1995) Neuronal apoptosis in HIV infection in adults. Neuropath. Appl. Neurobiol. 21: 218-227.

20. Gelbard HA, James HJ, Sharer LR, et al. (1995) Apoptotic neurons in brains from paediatric patients with HIV-l encephalitis and progressive encephalopathy. Neuropath. Appl. Neurobiol. 21: 208-217.

21. Sharma DP, Zink MC, Anderson M, et al. (1992) Derivation of neurotropic simian immunodeficiency virus from exclusively lymphocytotropic parental virus: Pathogenesis of infection in macaques. J. Virology 66: 3550-3556.

22. Anderson MG, Hauer D, Sharma DP, et al. (1993) Analysis of envelope changes acquired by SIV $_{\text {mac }} 239$ during neuroadaption in rhesus macaques. Virology 195: 616-626.

23. Gavrieli T, Sherman Y, Ben-Sasson SA. (1992) Identification of programmed cell death in situ via specific labeling of nuclear DNA fragmentation. J. Cell Biol. 119: 493501.

24. Mankowski TL, Spelman TP, Resselai HG, et al. (1994) Neurovirulent SIV replicates productively in CNS endothelial cells in vivo and in vitro. J. Virol. 68: 8202-8208.

25. Kent KA, Rud E, Corcoran T, et al. (1992) Identification of two neutralizing and eight non-neutralizing epitopes on simian immunodeficiency virus envelope using monoclonal antibodies. AIDS Res. Hum. Retroviruses 8: 1147-1151.

26. Seilhean D, Duyckaerts C, Vazeux R, et al. (1993) HIV-1-associated cognitive/motor complex: Absence of neuronal loss in the cerebral neocortex. Neurology 43: 14921499.

27. Clements JE, Anderson MG, Zink MC, Joag SV, Narayan O. (1994). The SIV model of AIDS encephalopathy: Role of neurotropic viruses in diseases. In: Price RW, Perry SW (eds). Research Publications-Association for Research in Nervous and Mental Disease. Raven Press, NY, Vol. 72, pp. 147-157.

28. Kodama T, Kestler III HW, Burns DP, et al. 
(1990) Nonhuman primate lentiviruses: Models for human infection. Dev. Biol. Stand. 72: 267-271.

29. Desrosiers RC, Hansen-Moosa A, Mori K, Bouvier DP, King NW, Ringler DJ. (1991) Macrophage-tropic variants of SIV are associated with specific AIDS-related lesions but are not essential for the development of AIDS. Am. J. Pathol. 139: 29-35.

30. Murray EA, Rausch DM, Lendvay J, Sharer LR, Eiden LE. (1992) Cognitive and motor impairments associated with SIV infection in rhesus monkeys. Science 255: 1246-1249.

31. Albina JE, Cui S, Mateo RB, Reichner JS. (1993) Nitric oxide-mediated apoptosis in murine peritoneal macrophages. J. Immunol. 150: $5080-5085$.

32. Ankarcrona M, Dypbukt JM, Brune B, Nicotera P. (1994) Interleukin-1 beta-induced nitric oxide production activates apoptosis in pancreatic RINm5F cells. Exp. Cell Res. 213: 172-177.

33. Talley AK, Dewhurst S, Perry SW, et al. (1995) Tumor necrosis factor alpha-induced apoptosis in human neuronal cells: Protection by the antioxidant $\mathrm{N}$-acetylcysteine and the genes $b c l-2$ and crmA. Mol. Cell. Biol. 15: 2359-2366.

Contributed by S. H. Snyder on March 18, 1996.
34. Woods KM, Chapes SK. (1993) Three distinct cell phenotypes of induced-TNF cytotoxicity and their relationship to apoptosis. J. Leukoc. Biol. 53: 37-44.

35. Bagetta G, Corasaniti MT, Berliocchi L, Navarra M, Finazzi-Agro A, Nistico G. (1995) HIV-1 gpl20 produces DNA fragmentation in the cerebral cortex of rat. Biochem. Biophys. Res. Commun. 211: 130-136.

36. Muller WE, Schroder HC, Ushijima H, Dapper J, Bormann J. (1992) gp120 of HIV-1 induces apoptosis in rat cortical cell cultures: Prevention by memantine. Eur. J. Pharmacol. 226: 209-214.

37. Groux H, Torpier G, Monte D, Mouton Y, Capron A, Ameisen JC. (1992) Activationinduced death by apoptosis in $\mathrm{CD}^{+}{ }^{+} \mathrm{T}$ cells from human immunodeficiency virus-infected asymptomatic individuals. J. Exp. Med. 175: 331-340.

38. Wiley CA, Achim CL. (1995) Human immunodeficiency virus encephalitis and dementia. Ann. Neurol. 38: 559-560.

39. Vaux DL, Haecker G, Strasser A. (1994) An evolutionary perspective on apoptosis. Cell 76: 777-779. 